\title{
Impact of electronic vaccine intelligence network application used in immunization sessions in Pune city
}

\author{
Damini S. Mahanubhav, Nandkumar M. Salunke, Sangita C. Shelke*, \\ Malangori A. Parande, Muralidhar P. Tambe
}

Department of Community Medicine, B. J. Government Medical College, Pune, Maharashtra, India

Received: 24 November 2021

Revised: 13 December 2021

Accepted: 14 December 2021

*Correspondence:

Dr. Sangita C. Shelke,

E-mail: drshelke@rediffmail.com

Copyright: (C) the author(s), publisher and licensee Medip Academy. This is an open-access article distributed under the terms of the Creative Commons Attribution Non-Commercial License, which permits unrestricted non-commercial use, distribution, and reproduction in any medium, provided the original work is properly cited.

\begin{abstract}
Background: Millions of deaths due to infectious diseases have been reduced globally as well as in India since inception of vaccination programme. In order to avoid the instances of cold chain failure and ensure constant monitoring of temperature of cold chain equipment's electronic vaccine intelligence network (eVIN) technology was adopted by Government of India.

Methods: A mixed methodology design with both qualitative as well as quantitative components were studied. This study was conducted in 16 immunization centres spread across the metropolitan Pune city in western Maharashtra.

Results: Vaccine beneficiaries increased for polio 814 (3.25\%), DPT1643 (21.79\%), MR $9615(23.02 \%)$ and IPV 2297 (23.58) vaccine after execution of eVIN app. Vaccine availability of BCG (6.04\%), Polio (20.02\%), MR (64.24\%), IPV $(11.38 \%)$ and hep B had increased as compared to the other vaccines. The vaccine wastage decreased for penta $(8.64 \%)$, IPV (123.98\%), TT (32.63\%) and hep B (47\%) vaccines post eVIN application compared to the pre eVIN. The qualitative study included in depth interviews, key informants' interview and focus group discussions. Various themes and subthemes emerged like the user-friendliness of app, difficulties faced by health care workers, their suggestions for improvements in the app.

Conclusions: The eVIN system is playing a pivotal role in effective and efficient management of vaccine supply, maintaining stock availability and monitoring. To reduce vaccine wastage usage of small dose vials in immunization sessions would be helpful.
\end{abstract}

Keywords: Vaccines, Cold chain, eVIN, FGD, Qualitative data, in-depth interview

\section{INTRODUCTION}

The Universal Immunization Programme (UIP) of India is one of the largest public health programmes in the world which provides immunization services to around 26 million new born and around 30 million pregnant women through 9 million sessions every year through 28,000 cold chain points. ${ }^{1}$

Millions of deaths due to infectious diseases have been reduced globally as well as in India since inception of vaccination programme. Besides decreasing mortality, it has also declined morbidity and the consequences of those diseases. Vaccines have played a major role in eradicating smallpox, controlling poliomyelitis and now through vaccination India aiming for the eradication of measles. ${ }^{2}$

Due to increasing trend in the vaccine stock out, approaches to be adopted to improve the vaccine stock management. Use of digital systems to monitor the stock are adopted to improve the stock position at vaccination centers. $^{3}$

A prompt and appropriate action is required by health care workers responsible for the maintaining the cold chain equipment's, in terms of correct storage of the vaccines as 
per the national guidelines, they must know correct use of various temperature monitoring devices, aptly responding to the temperature excursions, whenever problem arises. ${ }^{4}$

If cold chain management is done properly then it can help India in bringing down the cost of the immunization programme and also the wastage rate of various vaccines can be reduced remarkably causing positive impact on the public health. If India is adopting a digital health, it will help India in emerging as a global player as health is not included in union or concurrent list. ${ }^{6}$

In order to avoid the instances of cold chain failure and ensure constant monitoring of temperature of cold chain equipments Electronic vaccine intelligence network (eVIN) technology was adopted by Government of India. This technology combines features like IT infrastructure and trained human resources which helps in stock monitoring as well as monitoring of storage temperature of the vaccines kept at different multiple locations across the country.

eVIN has been installed across 28,000 vaccine delivery points and is very useful in maintaining stock across the vaccine storage centres in India. Around 50,000 temperature loggers have been installed as part of this application and around 49,000 government personnel have been engaged in the management of eVIN. ${ }^{1}$

In this system, all cold chain handlers are given smartphones having eVIN application which has various features. eVIN technology uses the smartphone, webbased application, temperature loggers and cloud-based server to digitize vaccine stock inventory and storage temperature of all the vaccine stores and cold chain points located at peripheral government health facilities. ${ }^{7}$ Every cold chain handler engaged in delivering immunization services enters the net utilization for each vaccine in the standardized registers at the end of every immunization day. This is simultaneously updated in the eVIN application and uploaded on a cloud server, which can then be viewed by programme managers at the district, state and national level through online dashboards. ${ }^{7}$

Earlier studies done in the past have studied the reduction in the utilization of the vaccines, thereby saving so many doses in post eVIN period, significant reduction in the stockout at various facilities. Vaccine flow network has been streamlined and other aspects like assessment of factors affecting vaccine cold chain management practices in public health have been rationalized. ${ }^{7,8}$

But these studies have not considered the effect of eVIN app on the vaccine beneficiaries, vaccine availability and difference in the wastage. The literature was also lacking in the area of user-friendliness of this application and experiences of health care workers who are engaged in delivering immunization services and are using this application. Hence to explore those aspects of this application, mix methodology study was undertaken including quantitative and qualitative aspects.

\section{METHODS}

\section{Study design}

To describe the features of the eVIN application used in immunization and to determine its usefulness, the present field based mixed methodology, observational study was undertaken. A mixed methodology design with both qualitative as well as quantitative components were studied.

\section{Setting}

This study was conducted in various immunization centres spread across the metropolitan Pune city in western Maharashtra.

For the present study data was collected over a period of two months, September and October 2021. The eVIN app was introduced in Pune city in the month of March 2019. Taking into consideration the difficulty of collecting data from records, it was decided to collect pre and post data; six months before and after implementation of eVIN app in the city for comparing pre and post data.

\section{Ethics approval}

The present study was approved by ethics committee of the institution, (Ethics Committee of BJ Government Medical College, Pune). Written permission from $\mathrm{MOH}$ (Medical Officer Health) was also obtained. Utmost care was taken to maintain privacy and confidentiality.

\section{Source and collection of data}

The data source used for quantitative data were various records in the form of registers and monthly reports maintained manually. The information was collected from registers maintained for daily temperature record of ILR and deep freezer for cold chain maintenance, stock availability of various vaccines, its wastage, indent register, beneficiaries register.

The qualitative data were gathered by conducting in-depth interviews of cold chain handlers, key informant interviews of medical officer including a city immunization officer. Focus group discussion of cold chain handlers involved in immunization sessions was conducted.

\section{Sample size}

Due to large number of immunization centres in the metropolitan city, study based on representative sample was proposed. The reduction in vaccine utilization rate at vaccination centre was taken as $29.6 \%$ for calculating sample size. ${ }^{8}$ 
$\mathrm{P}=29.6$ (reduction in vaccine utilization), C. $\mathrm{L} .=95 \%$, $\mathrm{e}=16 \%$. $^{8}$

$$
\begin{gathered}
Q=100-P=70.4 \\
N=\frac{Z^{2} \times P \times Q}{e^{2}}=32
\end{gathered}
$$

$\mathrm{P}$ of vaccine utilization

$$
Q=100-P
$$

E- absolute precision

Thus, for the present study the minimum samples to be included were 32 .

As, minimum 2 health care workers are employed in an immunization centre, of which, one is medical officer and the other is cold chain handler, they were to be selected as sample for the present study. Hence 16 immunization centres were selected from total 63 centres.

Systematic random sample technique was used to identify the study centres. The Pune corporation list of immunization centres was used as sampling frame. Every fourth centre was included in the study.

\section{Data analysis}

The quantitative data was analysed using SPSS software version 21. Continuous variables were summarized using means and Standard deviations (SD) for normally distributed data. Paired student ' $t$ ' test was applied to evaluate the difference in consumption and wastage of vaccine in two different era - before implementation of eVIN and after implementation of eVIN app. Statistical significance was evaluated using $95 \%$ confidence interval and a two tailed $\mathrm{p}$ value of $<0.05$.

The qualitative data was collected in form of recordings and notes. Prior permission was obtained for this from the health care workers interviewed or those participated in FGD.

The data collected was recorded in word document as transcript. It was edited to detect and correct errors or omissions. It was coded independently by two authors. The data was analysed to form themes and subthemes and verbatims were used for writing report.

\section{RESULTS}

Both quantitative and qualitative data was collected from sixteen immunization centres in the city. Difference in the number of beneficiaries for all vaccines before and after implementation of eVIN app was appraised. Cold chain maintenance was evaluated at all the centres in study by checking registers kept for temperature records of ILR and deep freezers but we could not find any significant difference in the cold chain in any of the centres. The temperatures of ILR ranged from $2^{\circ}-8^{\circ} \mathrm{C}$ only in both the scenario's before and after eVIN was established.

Calculated the difference in the number of beneficiaries for various vaccines before and after implementation of eVIN app. Vaccine beneficiaries increased for polio 814 (3.25\%), DPT1643 (21.79\%), MR 9615(23.02\%) and IPV 2297 (23.58) vaccine after execution of eVIN app. The beneficiaries were more in number for BCG, Penta, TT and Hep B vaccines prior to eVIN application (Table 1).

Difference in the availability of all vaccines at the immunization centres was calculated. Vaccine availability of BCG (6.04\%), Polio (20.02\%), MR (64.24\%), IPV $(11.38 \%)$ and hep B had increased as compared to the other vaccines before and after installation of eVIN application (Table 2).

Vaccine wastage for all vaccines was calculated as per the records available in the centres. The vaccine wastage decreased for Penta (8.64\%), IPV (123.98\%), TT (32.63\%) and hep B (47\%) vaccines post eVIN application compared to the pre eVIN. The vaccine wastage increased tremendously for BCG (64.29\%), Polio (71.09\%) and MR $(65.44 \%)$.

\section{Qualitative data analysis}

An interview guide was devised for conducting FGD. The in-depth and key informant interviews consisted of openended questionnaires. The issues included were how friendly is the eVIN app at the user end, had the workers undergone any training to use the app, what difficulties they faced, pros and cons of the app, do they suggest any improvements in the app, their perspectives in the immunization programme. There was profound agreement between answers given by key informants and the cold chain handlers.

There were 16 each key informants and cold chain handlers (Table 4). The cold chain handlers were all nursing staff with a mean age of 41.3 years. The key informants were younger in age and less experienced than the cold chain handlers. The qualitative research methodology comprised of answers to open-ended questionnaire of in-depth interview, key informant interview and FGD with cold chain handlers. The transcriptions were coded and recoded to develop themes and sub-themes, (Figure 1).

\section{Themes}

\section{Cold chain}

The primary function of eVIN app is to help cold chain handlers monitor cold chain of vaccines constantly. Both the key informants and cold chain handlers agreed the usefulness of eVIN app for monitoring cold chain. 
One of the medical officer working as incharge said, "Before eVIN app, it was very stressful to monitor cold chain for vaccines. We had to constantly keep a watch on thermoregulation of ILR very meticulously. Owing to this app, it is become so easy".

A PHN said, "I am so happy with the app and relaxed, otherwise even if I go home, the electricity issues in the city would bother me every now and then for cold chain issue. Since, this app informs us wherever we are, the life is become less worry some now".

Another staff nurse said, "Before to this app, early in the morning, whenever I came to the vaccination centre, my first job and priority always would be to go and monitor cold chain in ILR, to check if all vaccines are safe, the Vaccine vial monitor (VVM) is intact and the colour codes have not changed".

\section{App training}

Frequency and duration

All respondent said that only one training session was conducted for two days in the beginning before implementation of eVIN app.

It was hands on training session but after that no such training session was conducted.

So, the frequency of training should be increased i.e.; at least once or twice a year.

A female respondent 25 years said, "Booklet or user manual were provided to all cold chain handlers during training. Certificates of participation were also given to all. There should be frequent training programs to up-date our knowledge".

\section{Incentives}

One female respondent cold chain handler said, "If the senior officials from programme come for supervisory visits/training programme, they could appreciate our work and they could give us some kind of incentives to keep us motivated to do a good work further".

\section{Vaccine wastage option in eVIN}

Wastage option for vaccines following Open vial policy (OVP) and not following OVP

Altogether respondent said that there is no vaccine wastage option in the application for vaccine following open vial policy. Similarly, there is no vaccine wastage option in the application for vaccine not following open vial policy.

Respondent 5, a female said, "As there is no vaccine wastage option in the application so they can't show the wastage of vaccines which are not following open vial policy. Due to this wastage of BCG and MR has been increased".

Respondent 10 said, "MR vaccine wastage at my site is maximum as compared to other vaccines. This I feel is due to large vaccine vial which is ten dose vials. So, they should come up with both large and small dose vaccine vials. This will minimize wastage, as we can use small dose vials when number of beneficiaries are less and vice a versa."

\section{Vaccine indent}

Indent option

The eVIN app doesn't have indent option, participants wished to have this facility in the app.

Respondent 5 and 6 said, "We are doing manual indenting. If there is indent option in application, directly it will place our demand and would be very helpful for us".

\section{Notification of vaccine expiry}

The eVIN app doesn't have facility to notify expiry date of vaccines.

Entirely all (96\%) respondent said that if they get notification regarding vaccine expiry well in advance that will help them to use that vial earlier and thus indirectly reducing the vaccine wastage.

Respondent 3 said, "Even though, we use First in first out (FIFO) principle in vaccine use, but sometimes we are left with excess stock due to various reasons, it would be better if the app gives us alarm for near expiry vaccines, an alert system should be there which makes us alert at least two months prior to expiry date to reduce wastage of vaccines."

\section{Beneficiary tracking system}

The public health care system of India uses Mother and child care tracking system (MCTS) for monitoring and tracking mother and child for vaccination and other purposes. $^{9}$

The health care workers including the vaccination incharge medical officers felt that eVIN app too should work on similar platform.

Respondent 11 said, "There is no provision of number of beneficiaries in the application, if this option is included in the application, it will help us in beneficiary updates or beneficiary tracking”.

Respondent 16 said, "There should be provision of sending text message to parent of beneficiaries turning up for vaccination so that no dose is skipped or missed". 


\section{User-friendliness}

All respondent said that smartphone has been provided to all cold chain handler when they attended $1^{\text {st }}$ training of eVIN application.

Respondent 3 said, "Due to smartphone it is become very easy for us to do entry at any time or anywhere, on the same day or very next day of immunization session".

\section{Multiple user issues}

Respondent 11 also said, "There are multiple user at their immunization centre, so sometimes there is mismatching in entry of data or stock by the staff so it should be one handed".

\section{Network issues}

Respondent 11, 10, 5, 6, 13 said, "The smartphone provided to us is sometimes not working properly, it gets hang or sometimes there is network issue due to this reason we have to download the application in their own android phone".

Table 1: Total number of beneficiaries for all vaccines before and after eVIN operation.

\begin{tabular}{|c|c|c|c|c|c|c|}
\hline $\begin{array}{l}\text { Name of } \\
\text { vaccines }\end{array}$ & $\begin{array}{l}\text { Total beneficiaries } \\
\text { before eVIN }\end{array}$ & $\begin{array}{l}\text { Total beneficiaries } \\
\text { after eVIN }\end{array}$ & Difference & $\begin{array}{l}\% \\
\text { difference }\end{array}$ & $\begin{array}{l}\text { Paired ' } t \text { ' } \\
\text { test }\end{array}$ & P value \\
\hline BCG & 5847 & 4478 & -1369 & 30.57 & 1.69 & 0.11 \\
\hline Polio & 24199 & 25013 & 814 & 3.25 & 0.38 & 0.711 \\
\hline Penta & 15610 & 15439 & -171 & 1.10 & 0.11 & 0.91 \\
\hline DPT & 5895 & 7538 & 1643 & 21.79 & 2.00 & 0.06 \\
\hline MR & 7401 & 9615 & 2214 & 23.02 & 1.81 & 0.08 \\
\hline TT & 16616 & 11250 & -5366 & 47.69 & 1.96 & 0.06 \\
\hline IPV & 7443 & 9740 & 2297 & 23.58 & 1.20 & 0.24 \\
\hline Нер B & 4145 & 2395 & -1750 & 73.06 & 2.19 & 0.04 \\
\hline
\end{tabular}

Table 2: Difference (\%) of vaccines availability at centres before and after eVIN establishment.

\begin{tabular}{|c|c|c|c|c|c|c|}
\hline $\begin{array}{l}\text { Name of } \\
\text { vaccines }\end{array}$ & $\begin{array}{l}\text { Availability before } \\
\text { eVIN }\end{array}$ & $\begin{array}{l}\text { Availability after } \\
\text { eVIN }\end{array}$ & Difference & $\begin{array}{l}\% \\
\text { difference }\end{array}$ & T value & P value \\
\hline BCG & 16390 & 17445 & 1055 & 6.04 & 0.72 & 0.48 \\
\hline Polio & 52898 & 66142 & 13244 & 20.02 & 1.41 & 0.17 \\
\hline Penta & 30534 & 28941 & -1593 & 5.50 & 0.38 & 0.7 \\
\hline DPT & 23213 & 21637 & -1576 & 7.28 & 0.63 & 0.5 \\
\hline MR & 28764 & 80444 & 51680 & 64.24 & 2.55 & 0.02 \\
\hline TT & 32367 & 22544 & -9823 & 43.57 & 2.28 & 0.03 \\
\hline IPV & 18993 & 21432 & -2439 & 11.38 & 0.45 & 0.6 \\
\hline Hep B & 12281 & 4447 & -7834 & 176.16 & 2.06 & 0.05 \\
\hline
\end{tabular}

Table 3: Difference (\%) of vaccines wastage at centres before and after eVIN operation.

\begin{tabular}{|llllllll|}
\hline $\begin{array}{l}\text { Name of } \\
\text { vaccines }\end{array}$ & Wastage before eVIN & $\begin{array}{l}\text { Wastage after } \\
\text { eVIN }\end{array}$ & 1641 & Difference & $\begin{array}{l}\text { \% } \\
\text { difference }\end{array}$ & T value & P value \\
\hline BCG & 1414 & 5965 & 1055 & 64.29 & 0.69 & 0.5 \\
\hline Polio & 1724 & 405 & 4241 & 71.09 & 1.63 & 0.12 \\
\hline Penta & 440 & 180 & -35 & 8.64 & 0.11 & 0.9 \\
\hline DPT & 129 & 1852 & 51 & 28.33 & 0.45 & 0.6 \\
\hline MR & 640 & 95 & 1212 & 65.44 & 4.76 & 0.0003 \\
\hline TT & 126 & 1159 & -31 & 32.63 & 0.91 & 0.37 \\
\hline IPV & 2596 & 145 & -1437 & 123.98 & 1.21 & 0.2 \\
\hline Hep B & 214 & -69 & 47.58 & 0.63 & 0.5 \\
\hline
\end{tabular}

Table 4: Profile of key informants and cold chain handlers.

\begin{tabular}{|c|c|c|c|c|c|}
\hline \multirow{2}{*}{$\begin{array}{l}\text { Health care } \\
\text { workers }\end{array}$} & \multirow{2}{*}{ Mean age and SD } & \multirow{2}{*}{$\begin{array}{l}\text { Mean experience in } \\
\text { years and SD }\end{array}$} & \multicolumn{3}{|l|}{ Gender } \\
\hline & & & & $\mathbf{N}$ & $\%$ \\
\hline \multirow{2}{*}{$\begin{array}{l}\text { Key } \\
\text { informants }\end{array}$} & \multirow{2}{*}{$34.8 \pm 6.3$} & \multirow{2}{*}{$8.2 \pm 6.5$} & Male & 6 & 37.5 \\
\hline & & & Female & 10 & 62.5 \\
\hline
\end{tabular}




\begin{tabular}{|c|c|c|c|c|c|}
\hline \multirow{2}{*}{$\begin{array}{l}\text { Health care } \\
\text { workers }\end{array}$} & \multirow{2}{*}{ Mean age and SD } & \multirow{2}{*}{$\begin{array}{l}\text { Mean experience in } \\
\text { years and SD }\end{array}$} & \multicolumn{3}{|l|}{ Gender } \\
\hline & & & & $\mathbf{N}$ & $\%$ \\
\hline \multirow{2}{*}{$\begin{array}{l}\text { Cold chain } \\
\text { handlers }\end{array}$} & \multirow{2}{*}{$41.3 \pm 10.26$} & \multirow{2}{*}{$16.6 \pm 9.6$} & Male & 0 & 0 \\
\hline & & & Females & 16 & 100 \\
\hline
\end{tabular}

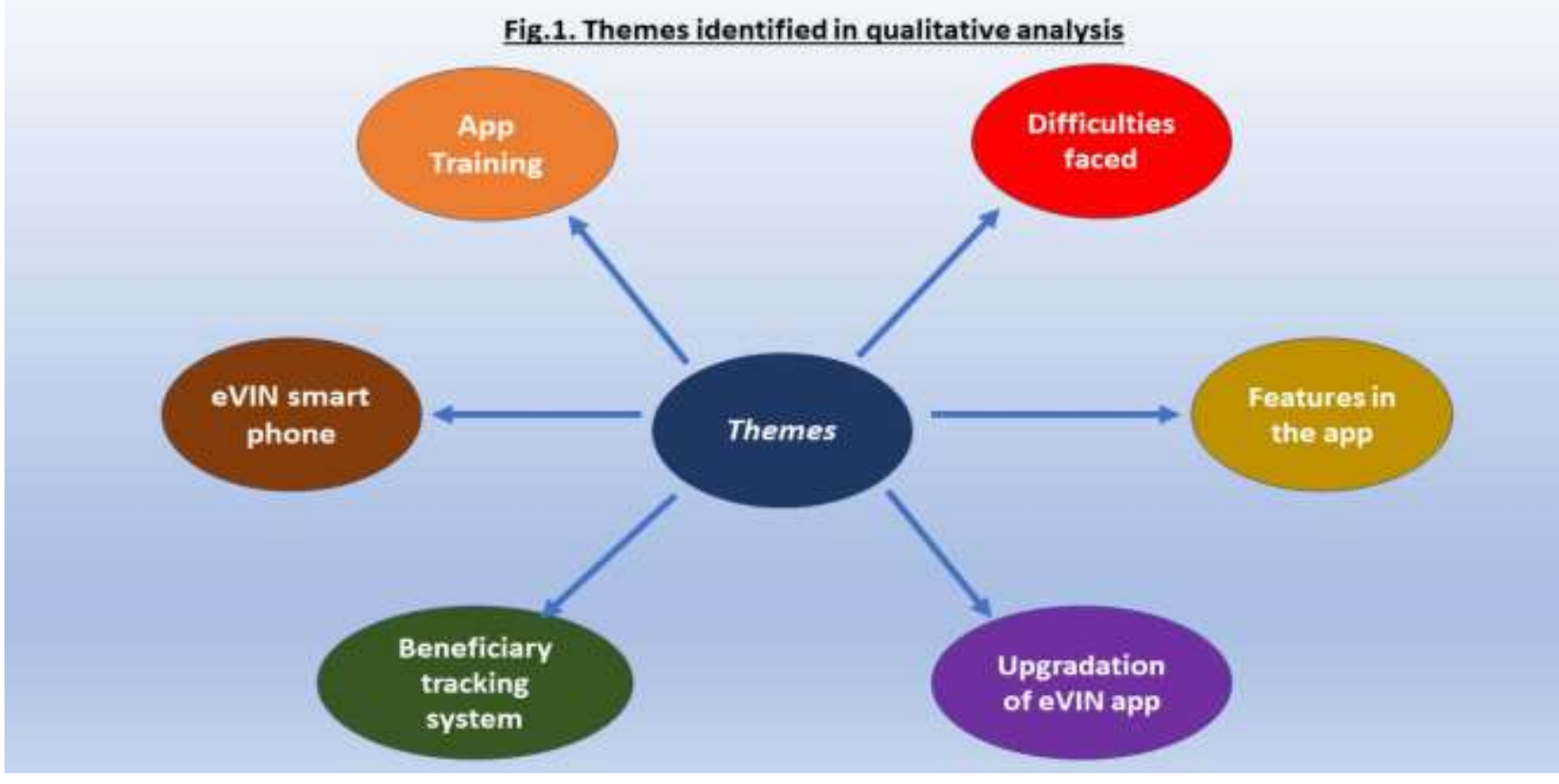

Figure 1: Themes identified in qualitative analysis.

\section{DISCUSSION}

eVIN technology was invented aiming to digitize vaccine stock inventory and cold chain monitoring at the site of storage including all cold chain points located at peripheral government health facilities. ${ }^{6,10}$

The study found that eVIN application has increased the vaccination coverage i.e.; number of beneficiaries have increased after the installation of this application especially for polio 814 (3.25\%), DPT 1643 (21.79\%), MR 9615 (23.02\%) and IPV 2297 (23.58) vaccines. This finding was against study conducted by Gurnani et al where they found the utilization of vaccines reduced from 305.3 million doses in pre-eVIN period to 215.0 million doses in posteVIN period, demonstrating $29.6 \%$ reduction in utilization of doses. ${ }^{7}$

When availability of vaccine at centres was assessed before and after installation of eVIN it was found that availability of doses for non-open vial policy vaccines had increased [BCG (6.04\%), MR (64.24\%), IPV (11.38\%) and hep B] had increased as compared to the other vaccines before and after installation of eVIN application. When assessment of vaccine wastage for various vaccines was done, it showed that there was significant increase in the wastage of MR vaccine as compared to other vaccines. This was post MR vaccination campaign in India, where MR vaccination in routine immunization was promoted. ${ }^{11}$ This could also be contributed to the fact that MR vaccines comes in ten dose vial, leading to increased wastage if the number of beneficiaries are less at the vaccination site. ${ }^{11} \mathrm{~A}$ vaccine wastage assessment study conducted by UNICEF in India in 2010 revealed that vaccine wastage documentation was poor at all levels. ${ }^{12}$

The cold chain handlers were satisfied with inception of eVIN app with minor setbacks. The nursing staff wished to upgrade the eVIN app on similar lines to the Mother and child tracking system (MCTS) so that the beneficiaries are benefited maximally. ${ }^{9}$

\section{Limitation}

The study included data six months before and after of eVIN app implementation in Pune city. It was difficult to retrieve pre-eVIN data beyond six months, due to nonavailability or completeness.

\section{CONCLUSION}

The eVIN system is playing a pivotal role in effective and efficient management of vaccine supply, maintaining stock availability, supervision and monitoring. Besides rigorous temperature monitoring, it is also essential that we do capacity building of the dedicated cold chain handlers for routine use of eVIN app. Regular constructive supervision and monitoring are needed to ensure cold chain reliability. To reduce vaccine wastage usage of both large and small dose vials in immunization sessions would be helpful. The 
app could be further upgraded as per the demands of health care workers working in immunization programme.

\section{ACKNOWLEDGEMENTS}

We would like to thank all the health care workers working in various immunization centres in Pune city for participating in the study and cooperating for collection of data from their records, for giving in-depth interviews, key informant interviews and participating in FGD.

Funding: No funding sources Conflict of interest: None declared

Ethical approval: The study was approved by the Institutional Ethics Committee

\section{REFERENCES}

1. Ministry of Health and Family Welfare, Government of India (MoHFW-GoI). Comprehensive Multi-Year Plan 2018-22. New Delhi: MoHFW-GoI; 2018.

2. Das MK, Arora NK, Mathew T, Vyas B, Devi SK, Yadav A. Temperature integrity and exposure of vaccines to suboptimal temperatures in cold chain devices at different levels in three states of India. Trop Dis Travel Med Vaccines. 2020;6:8.

3. Iwu CJ, Jaca A, Abdullahi LH, Ngcobo NJ, Wiysonge CS. Protocol for a systematic review of the effects of interventions for vaccine stock management. Syst Rev. 2019;8(1):14.

4. WHO. Vaccine vial monitor, 2011. Available at: http://www.who.int/immunization_standards/vaccin e_quality/vvm_10years_index/en. Accessed on 14 November 2021.

5. Peepliwal A. Cold Chain: A Lynchpin of National Immunization Program. J Pharma Techn Res Manag. 2017;5(1):77-104.
6. Sarbadhikari SN. Digital health in India- As envisaged by the National Health Policy. BLDE Univ J Health Sci. 2019;4:1-6.

7. Gurnani V, Singh P, Haldar P, Aggarwal MK, Agrahari K, Kashyap S, et al. Programmatic assessment of electronic Vaccine Intelligence Network (eVIN). PLoS One. 2020;15(11):0241369.

8. Bogale HA, Amhare AF, Bogale AA. Assessment of factors affecting vaccine cold chain management practice in public health institutions in east Gojam zone of Amhara region. BMC Public Health. 2019;19(1):1433.

9. Digital India. Mother and child tracking system (MCTS), 2019. Available at: https://digitalindia.gov.in/content/motherchildtrackn g-system-mcts. Accessed on 14 November 2021.

10. Thiyagarajan A, Bhattacharya S, Khaladkar D. Role of Electronic Vaccine Intelligence Network (eVIN) system for quality improvement in immunization data in India. CHRISMED J Health Res. 2019;6(2):128.

11. WHO. Frequently asked questions on MR vaccination campaign; a handbook for frontline health workers, 2021. Available at: http://www.searo.who.int/india/topics/measles/FAQ s/en. Accessed on 14 November 2021.

12. UNICEF, India. Assessment of Effective Vaccine Management in Maharashtra, 2011. Available at: http://www.itsu.org.in/repositoryresources/20.Mahar ashtraEVM 2011. Accessed on 14 November 2021.

Cite this article as: Mahanubhav DS, Salunke NM, Shelke SC, Parande MA, Tambe MP. Impact of electronic vaccine intelligence network application used in immunization sessions in Pune city. Int $\mathbf{J}$ Community Med Public Health 2022;9:130-6. 